\title{
Sciendo
}

\section{HUMAN-MACHINE COMMUNICATION AND CRISIS MANAGEMENT. AN AUTOMOTIVE INDUSTRY CASE STUDY}

\author{
Levente BAKOS
}

Sapientia Hungarian University of Transylvania, Faculty of Technical and Human Sciences, Târgu Mureș, Romania,bakos@ms.sapientia.ro

\begin{abstract}
The article presents some results of a larger study of crisis management in the automotive supply industry. This paper studies human - machine communication during organizational crises, an issue that can make the difference between success and failure. The topic is even more challenging in the highly standardized and regulated automotive industry. Using some methodologies taken from social sciences, we analyse the manner in which employees in the automotive supply industry handle unforeseen events. In spite of the increased number of standards and regulations, employees display ambiguous behaviour during unforeseen events, affecting trust in human-machine communication.
\end{abstract}

Keywords: human-machine communication, crisis management, risk management.

\section{Risk. Crisis. Communication}

In our dynamically changing world, risk management has become one of the most important tasks within organizations. The ever-changing conditions force even the strongest players to continually focus on their internal and external environment. Technological, financial, and market related risks require prudent and proactive behaviour from each player in these competitive markets. Increasingly, interdependence among the key players in the logistical chain demands that special attention is paid, not only to the moves of competitors and customers, but also to risk issues related to their business partners. The most common quality standard groups used in industry (ISO9000 [1], ISO 14000 [2]) devote a lot of attention to risk management. At the same time project management methodologies also provide practical and theoretical support for risk management [3]. devote a lot of attention to risk management. At the same time project management methodologies also provide practical and theoretical support for risk management [4] developed specifically for risk management, recommends the risk assessment procedure displayed in Figure 1. As we can see in the figure, the stan- dard recommends a cyclical risk assessment and evaluation, in order to identify as many risks as we can. In spite of these analyses proposed by the standards, beyond the countless regulations and many years of experience it is impossible to map all the risk factors. Even if it were possible, it is technically and economically meaningless to be prepared for everything. Organizations will always have to face situations for which they are unprepared; it's the nature of their evolution. If

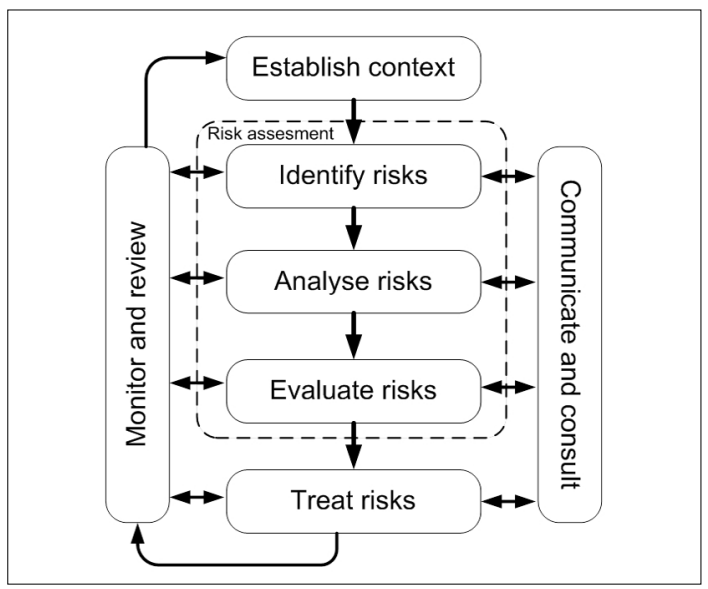

Figure 1. Risk assessment ISO 31000 [4] 
they cannot respond quickly to these incidents, in extremis, it may escalate into a crisis. By crisis, here, we mean an unexpected, sudden event that might have a major influence on the future of the entire organization. A crisis can be viewed as the perception of an event that threatens the important expectations of stakeholders and which can impact the organization's performance [5]. In our approach, there may be three basic scenarios for the development of a crisis. The first, probably the most common scenario, occurs when we have a situation which was (almost) impossible to anticipate. According to the second scenario, we have to deal with known risk factors, but the escalation of the situation is caused either by the simultaneous occurrence of multiple known factors or an unexpected combination of some factors. In the third case, the undesirable event is simply the result of a known factor, but with significantly higher intensity than expected. In principle, in all other cases, at the occurrence of a known risk, the risk management algorithms developed by the organization shall lead the organization to manage the situation effectively. In this approach, crisis management is nothing more than the management process that begins when the procedures developed by risk management are no longer applicable.

The real consequences of a crisis often occur long after the incident has happened, but the effects are deeply influenced by the initial response. In our approach, the outcome of a crisis can be positive, the organization finds itself in a better position after the crisis than it did before the incident [6]. We have to distinguish the shortterm and long-term effects of the crisis. If awareness is on the short-term effects, the goal might be to reduce only the material damage, while in the long-term perspective it is much more important to focus on reputation issues (Figure 2.).

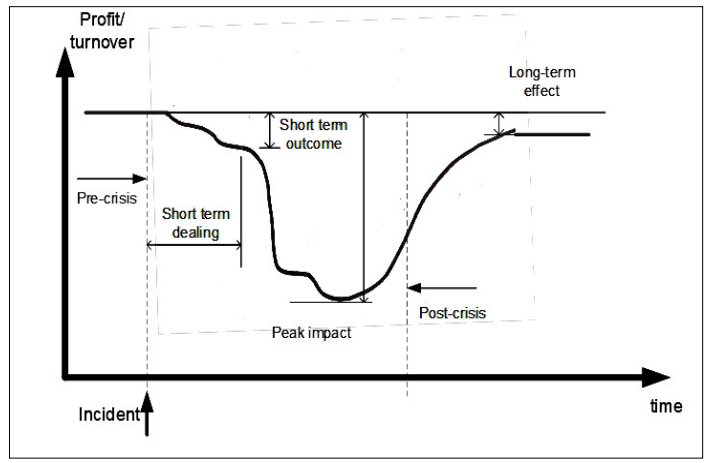

Figure 2. Short and long-term effects of a crisis
During the process of crisis management, both short-term effects and medium/long-term consequences must be taken into account. That is the reason why it is far from sufficient to focus only on the technical problems. Faulty crisis communication can cause more damage than the crisis itself! Communication issues are obviously important for effective troubleshooting, but communication with the authorities and with other stakeholders (for example customers, suppliers, press) is equally important. Defective communication or the lack of communication with the stakeholders might cost much more in long term than the current material damage [7]. Just think, for example, of a car test-drive failure, when there is crash due to a faulty suspension design. The real damage is not the dented hood, but the loses that will occur when it is subsequently disclosed that the company wanted to cover up the incident.

Nowadays, crisis communication, and within this, human-machine communication, is be-coming an increasingly important issue during the management of crisis situations. In our digitized world, we find it difficult to communicate without the support of digital technologies. Using the advantages provided by different gadgets, human-to-human communication often takes place with the support of smart phones, computers and other machines. The human-machine relationship is actually present almost every situation where people communicating are at widely separated locations. People involved in unexpected situations have the tendency to text or call for help, instead of using traditional human-human communication techniques, in spite of the fact that some of their colleagues might be located only few meters from them. The increasingly complex human-machine relationship is both the cause of risks and also a tool for effective crisis management [8].

\section{Human-machine interaction in crisis}

During unexpected events, two extreme forms of human-machine behaviour can occur. On the one hand, we might have over-reliance on the data and solutions provided by the available technological equipment. On the other hand, we may have at the other extreme, the overestimation of the abilities of the human resources. During the last few decades engineers have tried, and mostly succeeded, in automating most of the processes in industrial environments, leaving the rest to be handled by human operators [9]. Such situations 
might be the extreme unpredictable situations where the solution rests almost exclusively on human resources. In these cases, there is the chance of overestimating the abilities of the human operators [10]. This phenomenon, called the "magic-human" assumption, happens when we assume that the human operator will immediately perceive any abnormal situation, and will make perfect decisions even under bounded rationality conditions. (Figure 3.).

If we do not count the so-called Life Critical Systems, such as aviation, nuclear power plants, warfare technology or surgery, in the majority of human activities there is a lack of preparedness for the human-machine collaboration during unforeseen events [11]. The aim of our research is to examine how human resources cope with unforeseen events. We decided to study a sample from the automotive supplier industry in Eastern-Europe. The studied industry is characterized by a high level of standardization, each of the evaluated companies operates according to a strict system of international rules. We assumed that if we detect any unpreparedness or lack of preparedness at these organizations, then this phenomenon would probably be more prevalent in other industries. Being constrained by the length of this paper, we depict here only few descriptive statistics of the research related to:

- willingness to follow the rules during crises,

- reaction to a seemingly false warning message, - crisis response in the case of personal interest.

\section{Research methodology. Results}

Based on a mixed research methodology, drawing on the social sciences, we used two basic methods: interviews and a questionnaire-based survey. We carried out interviews with managers of 10 companies, and subsequently collected 151 responses from employees of the same orga-

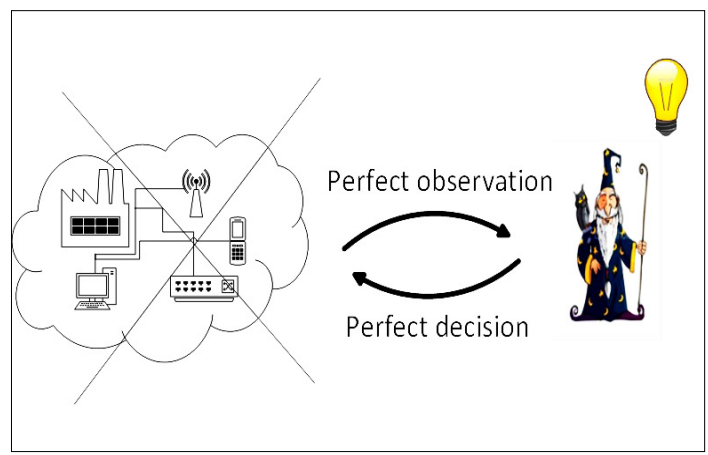

Figure 3. The 'Magic Human' effect [10] nizations. The respondents were mainly middle managers from technical departments. Among respondents there were included some non-managerial staff members, with key roles in the event of an emerging crisis. They were representatives of important areas such as fire protection, occupational safety or public relations. Due to their field of expertise, we assumed, they had outstanding problem-solving skills and better-than-average preparedness to deal with unpredictable situations.

Figure 4. shows the respondents 'willingness to follow the organization's rules in the event of a crisis. The figure shows that $40 \%$ of respondents agree that an emergency situation might require deviation from the regulations. At the same time, the proportion of those who definitely said "no" is also high. Almost a quarter (24\%) of respondents would adhere to the rules of the organization in all circumstances. They would do so, probably even in those cases where these rules blocked the situation from being resolved, or even if they were aware that the current situation was not thought of by the policy makers at the time the rules were written.

The intention to go beyond the rules shown in the figure, as only $23 \%$ of respondents would stick to the rules, is not entirely in line with the intentions shown in the next figure. Figure 5. indicates that in the event of an organizational disorder half of the respondents would turn to his / her supervisor for help, and would follow the rules, in spite of the fact that the solution to the problem is obviously not within the expertise field of the supervisor. As can be seen in Figure 5, in the event that the respondent evaluates that their computer is sending a fake warning message, half of the respondents turn to their boss to resolve the situation. This is the 'right' behaviour since, despite the emergency, the respondent's intention is to

\section{Would you go beyond the standards in a crisis situation?}

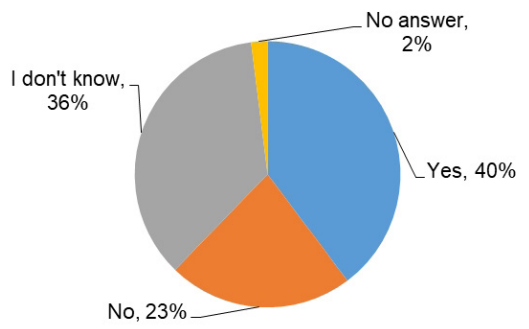

Figure 4. Willingness to follow the rules during crises 


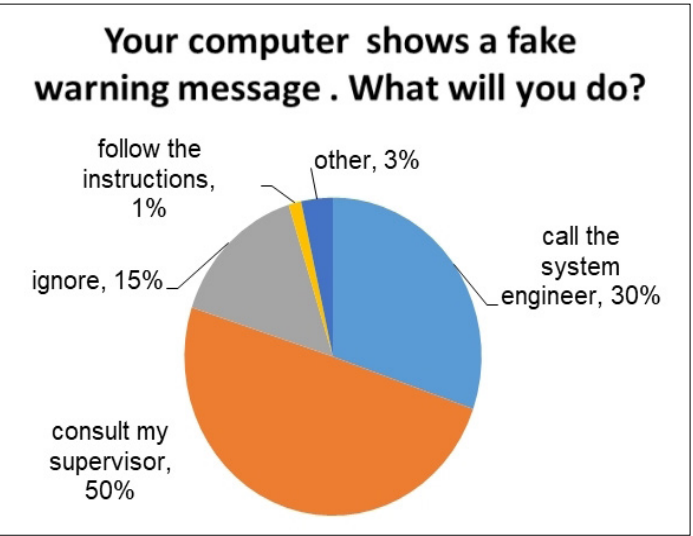

Figure 5. Reaction to a seemingly fake warning message

follow the organizational hierarchy and to have a disciplined professional attitude. Obviously, the problem-solving attitude would assume that the respondent turns to the system engineers or other IT staff. This option was chosen by $30 \%$ of respondents, while nearly $20 \%$ of respondents preferred solutions that were disadvantageous for the organization: a completely passive or overly creative behaviour. Interestingly, only $1 \%$ of respondents would be willing to follow the instructions provided by the computer, although the IT system was probably designed to warn the users if something was wrong.

In contrast to the answers provided to the previous question, there is fundamentally different way of thinking when the respondents see their own work in danger or feel that they are direct stakeholders of the given crisis situation. In these situations, they seemingly take a completely different position. Figure 6. shows that in such a case, $82 \%$ of respondents turn to the person from whom they hope for an immediate solution to their problem. Under these circumstances the hierarchical relations and the conformity to the regulations becomes a secondary issue. In contrast to the value of $50 \%$ given in the previous answer, here only $1 \%$ of the respondents would turn to their supervisor. A relatively large number of the rest of respondents (17\%) either declared they did not know what they would do, or they declared they would look for some creative solution. It seems, when the respondents realise their personal interest they will search for the most rational solution in those situations.

Later, by factorial analysis we demonstrated, using the ANOVA method and the Levene's homogeneity test, that this this search for rational be-

\section{Your data will be deleted within $\mathbf{1 0}$ minutes. Who do you call?}

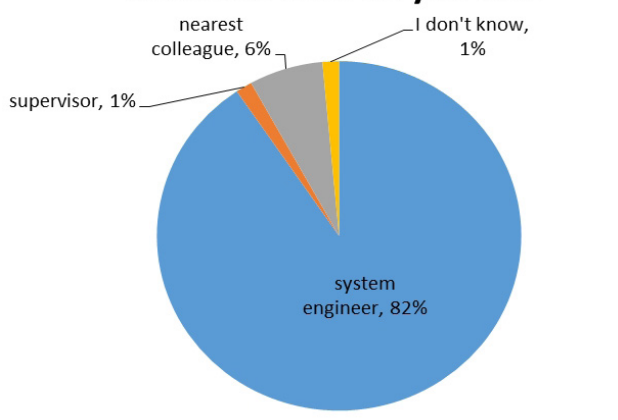

Figure 6. Crisis response in the case of personal interest

haviour is valid only in the case of medium intensity crises, and below or above a certain level the respondents did not provide concluding answers.

\section{Conclusions}

Human behaviour during crises may vary over a wide range. As a protagonist, people may adapt creatively to the situation and intuitively resolve the situation, but at the same time, they may become a passive witness, an idle victim of events. The speed of reaction is amplified by digital communication, being available to even the lowest ranking employee. These digital tools can be the cause and also the solution to certain situation. The man machine - collaboration can assess even the most complex situations in a matter of seconds, and in other cases, surprisingly, the spoiled man-machine connection blocks progress in routine situations.

Our research has confirmed that during their momentary instinctive behaviour, humans are able to keep their own interests in mind, even in the most complex situations. The results show that despite the high level of standardization, or maybe because of this, in unforeseen situations in the automotive supply industry, employees are likely to react chaotically. Under the hypothetical conditions formulated by the questionnaire, the respondents were uncertain about the possible alternatives; their reaction will undoubtedly be even more unpredictable in real situations. Therefore, we consider it important to make employees aware during the drills, training and other prevention activities, of their responsibilities. They have a responsibility to deal with any situation, regardless of whether that situation is 
included, or not, in their job description. The lack of rules does not yet absolve them of responsibility. Research has shown (see e.g. [12]), that if employees are aware of their responsibilities, they will have a much more proactive behaviour, and thereby they will naturally take more active role in the prevention and management of unexpected events. The interviews with the managers of the surveyed companies clearly show the faith in their employees, and even we have found the 'magic human' effect. However, the answers to the questions show that the middle managers and employees are far from prepared to deal with unforeseen situations.

In the case of the automotive supplier companies examined, human resources are not sufficiently mature to deal with crisis-like situations. Among the examined suppliers, despite operating according to international standards, the human-machine relationship is efficient only within the predetermined operating framework. The trust in computer-based equipment in the case of crises is not statistically conclusive, the behaviour of the respondents is statistically ambiguous.

The respondents are aware of the importance of human machine communication during crises. The results show that human-machine interaction during a crisis is a very important parameter for effective crisis management. In our sample we found answers that reveal unconditional trust in digital communication gadgets, as well as complete distrust in these means of communication. In the examined organizations, for the cases when unforeseen events occur, except for the areas of occupational safety and fire protection (this is not covered here), the organization did not develop general procedures for unpredictable situations. The lack of these provisions makes crisis management rigid and time-consuming, leaving the solution to the CEO level of the organizations

\section{References}

[1] MSZ EN ISO 9001:2015. Minőségirányítási rendszerek. Követelmények, 2015.

[2] EN ISO 14001:2015. Környezetközpontú irányítási rendszerek. Követelmények, 2015.

[3] ${ }^{* * *}$ A guide to the project management body of knowledge (PMBOK® guide). Fifth edition, Project Management Institute, 2013.

[4] MSZ ISO 31000:2018. Kockázatmenedzsment. Irányelvek, 2019.

[5] Barton L.: Crisis in Organisations: Managing and CommunicatingintheHeatofChaos.South-Western College Publishing, Cincinatti, 1993. 2.

[6] Coombs W. T., Holladay S. J: The Handbook of Crisis Communication. Malden: MA, Wiley-Blackwell, 2010. 20.

[7] Patterson B.: Crises impact on reputation management. Public Relations Journal, 49/11. (1993) $47-48$.

[8] Valckenaers P., Van Brussel H.: Design for the unexpected. From holonic manufacturing systems towards a humane mechatronics society. Butterworth-Heinemann, Leuven, Belgium, 2015.

[9] Boy G. A.: Dealing with the Unexpected in our Complex Socio-Technical World. 12th IFAC Symposium on Analysis, Design, and Evaluation of Human-Machine Systems, August 11-15, 2013. Las Vegas, NV, USA, 2013. 402-409.

[10] Trentesaux D., Millot P.: A human-centred design to break the myth of the "Magic Human" in intelligent manufacturing systems. In: Service orientation in holonic and multi-agent manufacturing. (Szerk.: Borangiu T., Trentesaux D., Thomas A., McFarlane D.). 2016). 103-113.

[11] Pacaux-Lemoine M.-P. et al: Designing intelligent manufacturing systems through Human-Machine Cooperation principles: A human-centered approach. Computers \& Industrial Engineering C, 111. (2017) 581-595.

[12] Tweedy J. T.: Introduction to Hazard Control Management. A Vital Organizational Function. CRC Press, London - New York, 2014. 